\title{
COMPOSIÇÃO QUÍMICA, COMPOSTOS BIOATIVOS \\ E DISSIMILARIDADE GENÉTICA ENTRE CULTIVARES DE AMOREIRA (Rubus spp.) CULTIVADAS NO SUL DE MINAS GERAIS ${ }^{1}$
}

\author{
MAYARA NEVES SANTOS GUEDES ${ }^{2}$, LUANA APARECIDA CASTILHO MARO ${ }^{3}$, \\ CELESTE MARIA PATTO DE ABREU ${ }^{4}$, RAFAEL PIO ${ }^{5}$, LEONARDO SILVA PATTO ${ }^{6}$
}

RESUMO - Frutos das cultivares Arapaho, Brazos, Caingangue, Cherokee, Choctaw, Comanche, Ébano, Guarani, Tupy e Xavante, e uma espécie de amoreira-vermelha (Rubus rosifolius Smith) foram avaliados quanto à composição química. Avaliou-se também a variação genética entre as cultivares de amoreira-preta e a espécie de amoreira-vermelha. Os resultados demonstraram variações na composição química dos frutos estudados. A amora- vermelha apresentou menor teor de umidade e maiores valores para os componentes cinzas, açúcares totais, açúcares redutores, açúcares não redutores, pectina total, pectina solúvel, fenóis, flavonoides, licopeno, $\beta$-caroteno e vitamina A. Os teores de umidade e antocianinas, a porcentagem de solubilização e a atividade antioxidante foram maiores nos frutos da cultivar Ébano. Verificou-se que os frutos da amoreira-vermelha e da cultivar Ébano apresentaram o maior grau de divergência genética para as variáveis analisadas. Isto indica a possibilidade de uso das mesmas em programas de melhoramento que visem à melhoria da composição química.

Termos para Indexação: Amora-preta, amora-vermelha, carotenoides, pectina, flavonoides, antocianinas.

\section{CHEMICAL COMPOSITION, BIOACTIVE COMPOUNDS AND GENETIC DISSIMILARITY AMONG CULTIVARS BLACKBERRY (Rubus spp.) CULTIVATED IN SOUTH MINAS GERAIS}

\begin{abstract}
Fruit cultivars Arapaho, Brazos, Caingangue, Cherokee, Choctaw, Comanche, Ébano, Guarani, Tupy and Xavante and a specie of redberry (Rubus rosifolius Smith), were evaluated for chemical composition. We also evaluated the genetic variation among cultivars blackberry and specie of redberry. The results demonstrate variations in the chemical composition of the fruits studied. Redberry showed lower humidity content and values for virtually components ash, total sugars, reducing sugars, non-reducing sugars, total pectin, soluble pectin, phenols, flavonoids, lycopene, $\beta$-carotene and vitamin A. With the exception of moisture, the anthocyanins, the percentage of solubilization and the antioxidant activity, which showed higher in fruit of Ébano cultivar. It was also found that fruits of redberry and Ébano cultivar showed the highest degree of genetic divergence for the analyzed variables. This indicates the possibility of using them in breeding programs aimed at improving the chemical composition.
\end{abstract}

Index Terms: Blackberry, redberry, carotenoids, pectin, flavonoids, anthocyanins.

\footnotetext{
'(Trabalho 230-13). Recebido em: 02-07-2013. Aceito para publicação em: 07-02-2014.

${ }^{2}$ Eng. Agr., M.Sc., Discente do Programa de Pós-graduação em Agroquímica, Universidade Federal de Lavras - UFLA, Dep. de Química, Caixa Postal 3037, 37200-000, Lavras-MG. E-mail: maysantos2@yahoo.com.br

${ }^{3}$ Eng. Agr., Pesquisadora Dra. Empresa de Pesquisa Agropecuária e Extensão Rural de Santa Catarina- Epagri, Itajaí, SC. E-mail: luanamaro@epagri.gov.sc.br.

${ }^{4}$ Eng. Agr., D.Sc., Universidade Federal de Lavras - UFLA, Dep. de Química, Caixa Postal 3037, 37200-000, Lavras-MG. Bolsista Produtividade em Pesquisa CNPq. E-mail: celeste@ufla.br

${ }^{5}$ Eng. Agr., D.Sc., Universidade Federal de Lavras - UFLA, Dep. de Agricultura, Caixa Postal 3037, 37200-000, Lavras-MG. Bolsista Produtividade em Pesquisa CNPq. E-mail: rafaelpio@dag.ufla.br

${ }^{6}$ Eng. Agr., M.Sc., Discente do Programa de Programa de Pós-Graduação em Agronomia, Universidade Tecnológica Federal do Paraná - UTFPR, Câmpus Pato Branco Via do Conhecimento, PR Km 1, Cep.85503-390. Pato Branco- PR. E-mail: leleospatto@hotmail.com
} 


\section{INTRODUÇÃO}

$\mathrm{O}$ interesse pelo consumo da amora-preta (Rubus spp.) aumentou nos últimos anos, devido a seus frutos possuírem quantidades expressivas de compostos fenólicos e carotenoides, que podem auxiliar no combate a doenças degenerativas (ALI et al., 2011), bem como nas quantidades expressivas de vitaminas, minerais e fibras (GUEDES et al., 2013). Além desses compostos, podem-se destacar os pigmentos naturais, principalmente a antocianina, que confere uma coloração atraente no processamento de seus frutos, na confecção de produtos lácteos, geleias e doces em calda (ACOSTA-MONTOYA et al., 2010).

Essa fruteira vem apresentando boa adaptação em clima subtropical. Campagnolo e Pio (2012a) registraram $6.430 \mathrm{~kg} \mathrm{ha}^{-1}$ com a cultivar Tupy, em Santa Helena-PR (clima Cfa, zona subtropical úmida). No município de Marechal Cândido Rondon-PR, que possui condições climáticas similares, a produtividade da cultivar Brazos foi de $18.602,5 \mathrm{~kg} \mathrm{ha}^{-1}$, da 'Guarani' 15.129,8 kg ha-1 e da 'Choctaw' 11.395,9 $\mathrm{kg} \mathrm{ha}^{-1}$ (CAMPAGNOLO; PIO, 2012b). Outra aposta é a amoreira-vermelha (Rubus rosifolius), nativa da serra da Mantiqueira e que produz frutos de aspecto visual bastante atrativo e sabor peculiar. A produção de frutos por planta é bem elevada (1.136 frutos), o que pode propiciar uma produtividade de $11.395,9 \mathrm{~kg} \mathrm{ha}^{-1}$ em regiões de clima subtropical (CAMPAGNOLO; PIO, 2012b).

No caso da amoreira-preta, as características quanto à adaptação climática, as mais diversas regiões de cultivo e as propriedades físicas e químicas de seus frutos são divergentes (FIGUEIREDO et al., 2013). Podem ocorrer variações nos teores dos compostos químicos em função do local onde são cultivadas, devido a diferenças na intensidade de radiação solar e amplitude térmica, que influenciam nas características organolépticas dos frutos da amoreira-preta (ALI et al., 2011; GUEDES et al., 2013).

Este trabalho objetivou avaliar a composição química, os compostos bioativos e a dissimilaridade genética entre cultivares de amoreira cultivadas nas condições subtropicais do sul de Minas Gerais.

\section{MATERIAL E MÉTODOS}

O experimento foi conduzido no Departamento de Química (DQI) da Universidade Federal de Lavras (UFLA), Lavras-MG. Foram avaliados frutos de 10 cultivares de amoreira-preta (Rubus spp.): Arapaho, Brazos, Caingangue, Cherokee, Choctaw, Comanche,
Ébano, Guarani, Tupy e Xavante, e uma espécie de amoreira-vermelha (Rubus rosifolius Smith), quanto à composição química. Os frutos foram coletados de plantas estabelecidas no município de Lavras ( $21^{\circ} 14^{\prime}$ $\mathrm{S}, 45^{\circ} 00^{\prime} \mathrm{O}$, a uma altitude média de 918 metros). $\mathrm{O}$ clima da região é do tipo $\mathrm{Cwb}$, temperado chuvoso (mesotérmico), com inverno seco e verão chuvoso, subtropical, com temperatura do mês mais quente maior que $22^{\circ} \mathrm{C}\left(22,1^{\circ} \mathrm{C}\right.$ em fevereiro), segundo classificação de Köppen.

Foi utilizado um quilo de frutos de cada cultivar, coletados no estádio de maturação comercial, com drupetes totalmente negros para as amoras-pretas e superfície vermelha para a amoravermelha. Após a seleção para ausência de injúrias mecânicas e fisiológicas, a amostra foi dividida em quatro partes de $0,25 \mathrm{~kg}$, as quais constituíram as repetições. Os frutos foram avaliados segundo os teores de umidade (\%), cinzas (\%) e vitamina A (mcg. $\left.100^{-1} \mathrm{gMF}\right)$ - de acordo com as normas da Association of Official Analytical Chemists - AOAC, e descrição de Maro et al. (2013); açúcares totais $\left(\mathrm{g} .100 \mathrm{~g}^{-1}\right)$, açúcares redutores $\left(\mathrm{g} .100 \mathrm{~g}^{-1}\right)$ e açúcares não redutores $\left(\mathrm{g} .100 \mathrm{~g}^{-1}\right)$ - determinados pelo método de Dische; pectina solúvel (mg. $\left.100 \mathrm{~g}^{-1} \mathrm{MF}\right)$, pectina total (mg. $\left.100 \mathrm{~g}^{-1} \mathrm{MF}\right)$ e porcentagem de solubilização das pectinas (\%) - foram extraídas segundo a técnica padronizada por McCready e McComb, e a porcentagem de solubilização das pectinas foi obtida pela porcentagem de pectina solúvel em relação à pectina total; fenóis totais (mg. $\left.100 \mathrm{~g}^{-1} \mathrm{MF}\right)$ - a extração dos compostos fenólicos foi realizada com metanol a $50 \%$, em refluxo, por três vezes consecutivas, a $80^{\circ} \mathrm{C}$, e os extratos, reunidos e evaporados a $25 \mathrm{~mL}$, sendo os fenólicos totais doseados pelo método de FolinDenis; flavonoides (mg.100 ${ }^{-1} \mathrm{MF}$ ) e antocianinas (mg.100g ${ }^{-1} \mathrm{MF}$ ) - a determinação monomérica foi efetuada pelo método $\mathrm{pH}$ diferencial, e os resultados foram expressos em mg de cianidina-3-glicosídeo por $100 \mathrm{~g}$ de matéria fresca; licopeno $\left(\mu \mathrm{g} .100 \mathrm{~g}^{-1} \mathrm{MF}\right)$ e $\beta$ - caroteno ( $\left.\mu \mathrm{g} .100 \mathrm{~g}^{-1} \mathrm{MF}\right)$ - as amostras foram homogeneizadas com uma mistura de acetona e hexano (2:3) e levadas para leitura de absorbância em espectrofotômetro, em quatro comprimentos de onda (453; 505; 645 e $663 \mathrm{~nm})$; atividade antioxidante $\left(\mathrm{EC}_{50}, \mathrm{mg} \cdot \mathrm{mg} \mathrm{DPPH}^{-1}\right)$ - conforme descrição de Maro et al. (2013), utilizando o método do sequestro do DPPH.

O delineamento experimental utilizado foi o inteiramente ao acaso, sendo os frutos das 10 cultivares de amoreira-preta e uma de amoreiravermelha, totalizando 11 tratamentos, com quatro repetições. Os dados foram submetidos à análise de variância (ANOVA), e as médias, comparadas 
pelo teste de Scott-Knott, a 5\% de probabilidade (FERREIRA, 2011).

Com o objetivo de explicar a variação genética entre as cultivares de amoreira, foram realizadas análises multivariadas (MANOVA). Como medida de dissimilaridade, usou-se a Distância Generalizada de Mahalanobis. Calculou-se a importância relativa das características (variávies canônicas). No processo de agrupamento, utilizaram-se os métodos UPGMA (Unweighted Pair-Group Method Using an Arithmetic Average) e de Otimização de Tocher aplicada a distância Euclideana Média. Os dados foram analisados, utilizando-se do programa GENES.

\section{RESULTADOS E DISCUSSÃO}

O teor de umidade dos frutos de todas as cultivares de amoreira-preta apresentou-se elevado, variando de $88,09 \%$ a $91,48 \%$ e teor de cinzas variando de $0,33 \%$ a $0,46 \%$, que não diferiram entre si. A amora-vermelha apresentou menor teor de umidade, porém maior quantidade de cinzas (Tabela 1). Houve formação de diferentes grupos para os teores de açúcares (Tabela 1). Nos frutos da amoravermelha, foi constatado o maior valor para açúcares

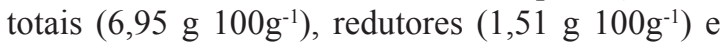

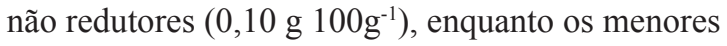
foram encontrados nos frutos da cultivar Tupy

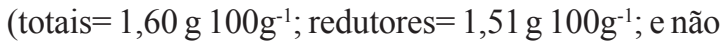

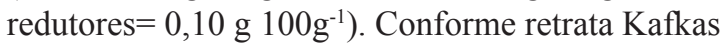
et al. (2006), o acúmulo de açúcar nos frutos exerce grande importância em sua fisiologia pós-colheita, em especial a frutose, que é o açúcar responsável pela doçura. Os teores de açúcares obtidos no sul de Minas para as amoras-pretas são menores que 5\% de açúcares totais encontrado por Kafkas et al. (2006). Esta diferença pode estar relacionada às condições subtropicais do sul de Minas, caracterizado pelas temperaturas mais elevadas na primavera e no verão, o que deve ter propiciado menor síntese de açúcares.

Frutos da amoreira-vermelha apresentaram maior teor de pectina total $\left(1.282,61 \mathrm{mg} \cdot 100 \mathrm{~g}^{-1} \mathrm{MF}\right)$, enquanto o teor mais baixo foi observado na cultivar Ébano (605,36 mg.100 $\left.\mathrm{g}^{-1} \mathrm{MF}\right)$, com diferença de $18,4 \%$ (Tabela 2). Antunes et al. (2006), em clima Cwa (tropical de altitude), na região de Caldas-MG, observaram maiores teores de pectina total para a 'Comanche' (600,0 mg.100 $\left.\mathrm{g}^{-1} \mathrm{MF}\right)$ e menores para a 'Ébano' (340,00 mg.100g-1 MF), com diferença de aproximadamente $43,3 \%$.

Dentre os frutos avaliados, a amora-vermelha apresentou maior teor de pectina solúvel, média de $576,18 \mathrm{mg} \cdot 100 \mathrm{~g}^{-1}$, que as cultivares de amora-preta (Tabela 2). A maior solubilização de pectinas foi observada nos frutos da 'Xavante' e da 'Ébano', com, respectivamente, $62,21 \%$ e $60,69 \%$ do teor da pectina total. Frutos com elevado percentual de pectina solúvel geralmente têm textura fraca e são pouco resistentes ao transporte e armazenamento (ANTUNES et al., 2006).

$\mathrm{O}$ teor de fenóis totais foi maior nos frutos de amora-vermelha (1.093,22 mg.100 $\left.\mathrm{g}^{-1}\right)$; e o menor, nos da cultivar Guarani (147,86 mg.100 $\left.\mathrm{g}^{-1}\right)$, diferindo estatisticamente das demais cultivares avaliadas (Tabela 3). Tosun et al. (2008) relataram teores médios de fenóis totais de $938,8 \pm 125,9$ mg.100 g ${ }^{-1}$, em frutos de amoreiras-pretas produzidos na Turquia.

Quanto ao teor de flavonoides, o maior teor também foi encontrado na amora- vermelha, seguida das cultivares Xavante e Choctaw, com 136,07 mg.100g ${ }^{-1}, 128,53$ mg. $100 \mathrm{~g}^{-1}$ e $102,70 \mathrm{mg} \cdot 100 \mathrm{~g}^{-1}$, respectivamente (Tabela 3). A variação nos teores de flavonoides nestes frutos é influenciada pelo genótipo, permitindo que, através de melhoramento genético, seja possível desenvolver materiais com concentrações elevadas de flavonoides e, portanto, maiores propriedades nutracêuticas. Verificaram-se também os menores teores de antocianinas na amoravermelha $\left(92,96 \mathrm{mg} 100 \mathrm{~g}^{-1}\right)$, enquanto a quantidade de antocianinas nos frutos de amora-preta variaram de 292,80 a 656,05 mg.100g-1. Segundo Chiang et al. (2005), frutos de diferentes genótipos de amora-preta originados de diferentes locais apresentam variação nos teores de antocianinas.

Encontraram-se também teores mais altos de $\beta$-caroteno e vitamina A nos frutos da amoravermelha, assim como grande variabilidade entre as cultivares da amora-preta, com os menores teores nas cultivares Guarani e Brazos (Tabela 3). Quanto ao licopeno, a afirmação de Moritz e Tramonte (2006), que sua concentração está ligada à coloração vermelha dos frutos, explica sua ausência em amorasvermelhas, cuja coloração foi bem menos intensa que nas pretas.

A atividade antioxidante ou sequestradora do radical DPPH variou de acordo com a cultivar (Tabela 3). O maior sequestro do radical DPPH foi observado em extratos da 'Ébano', salientando que, quanto menor o valor de $\mathrm{EC}_{50}$, maior a atividade antioxidante do composto analisado. $\mathrm{O}$ mais alto valor de $\mathrm{EC}_{50}$ foi observado na 'Comanche', uma atividade de captura do radical DPPH 3,2 vezes menor que a observada para a 'Ébano'. O resultado de $\mathrm{EC}_{50}$ observado para a cultivar Arapaho foi o menor $\left(2,27\right.$ mg.mg DPPH $\left.{ }^{-1}\right)$, juntamente com a cultivar Xavante $\left(2,30 \mathrm{mg} \cdot \mathrm{mg} \mathrm{DPPH}^{-1}\right)$.

$\mathrm{O}$ grau de divergência genética, ou seja, as estimativas de dissimilaridade, com base na Distância 
Generalizada de Mahalanobis entre as cultivares e a espécie de amora-vermelha são apresentadas na Tabela 4. O maior grau de divergência genética foi entre a amora-vermelha e a cultivar Ébano $\left(\mathrm{D}^{2}=2,75\right)$, indicando que esses genótipos foram os mais divergentes, e a menor dissimilaridade foi entre as cultivares Brazos e Guarani $\left(\mathrm{D}^{2}=0,50\right)$, consequentemente os mais similares.

Cada variável canônica é uma combinação linear das variáveis originais analisadas e as duas principais devem explicar mais de $80 \%$ da variância total entre os materias analisados. Neste trabalho, as duas primeiras variáveis canônicas explicaram cerca de $95,11 \%$ da variação total $(86,90 \%$ para a primeira e $8,21 \%$ para a segunda), o que possibilitou a dispersão gráfica no espaço bidimensional, revelando que a espécie de amora- vermelha (1) está distanciada das demais cultivares de amora-preta, enquanto as cultivares Arapaho (2) e Xavante (11), e a Brazos (3) e Guarany (4), as mais próximos (Figura 1). Isto também é indicado no dendograma de similaridade, assim como a maior divergência entre a cultivar Ébano e amora-vermelha (Figura 2).

$\mathrm{O}$ agrupamento pelo método de Tocher revelou a formação de dois grupos: o grupo I inclui todas as cultivares de amora-preta, e o grupo II, formado por apenas a espécie de amora-vermelha (Tabela 5). Isto indica a elevada dissimilaridade genética entre a espécie de amora-vermelha e as cultivares de amora preta.

Tendo-se que a análise multivariada de componentes principais, o agrupamento pelo dendograma e a otimização de Tocher são tidos como muito confiáveis na identificação de progenitores com alta divergência, e para orientar cruzamentos promissores, tem-se neste trabalho que a amoravermelha e a cultivar Ébano se destacaram, pela dissimilaridade genética, indicando que estes genótipos podem ser utilizados em programas de melhoramento através de cruzamentos com os outros genótipos.

TABELA 1- Teores médios de umidade, cinzas, açúcares totais (AT), açúcares redutores (AR) e açúcares não redutores (ANR) em frutos de cultivares de amoreira. UFLA, Lavras-MG, 2013.

\begin{tabular}{lccccc}
\hline Espécie/Cultivares & Umidade $\mathbf{( \% )}$ & Cinzas $\mathbf{( \% )}$ & $\mathbf{A T}\left(\mathbf{g . 1 0 0 \mathbf { g } ^ { - 1 }}\right)$ & $\mathbf{A R} \mathbf{( g . 1 0 0 \mathbf { g } ^ { - 1 } )}$ & $\left.\mathbf{A N R} \mathbf{( g . 1 0 0 \mathbf { g } ^ { - 1 }}\right)$ \\
\hline Amora-vermelha & $78,74 \mathrm{~b}$ & $0,78 \mathrm{a}$ & $6,95 \mathrm{a}$ & $6,43 \mathrm{a}$ & $0,54 \mathrm{a}$ \\
Arapaho & $88,74 \mathrm{a}$ & $0,42 \mathrm{~b}$ & $3,09 \mathrm{c}$ & $2,93 \mathrm{c}$ & $0,16 \mathrm{~d}$ \\
Brazos & $90,09 \mathrm{a}$ & $0,35 \mathrm{~b}$ & $2,58 \mathrm{e}$ & $2,44 \mathrm{e}$ & $0,15 \mathrm{~d}$ \\
Caingangue & $89,72 \mathrm{a}$ & $0,42 \mathrm{~b}$ & $3,05 \mathrm{c}$ & $2,87 \mathrm{c}$ & $0,18 \mathrm{c}$ \\
Cherokee & $89,58 \mathrm{a}$ & $0,46 \mathrm{~b}$ & $2,56 \mathrm{e}$ & $2,40 \mathrm{e}$ & $0,16 \mathrm{~d}$ \\
Choctaw & $88,09 \mathrm{a}$ & $0,45 \mathrm{~b}$ & $3,56 \mathrm{~b}$ & $3,36 \mathrm{~b}$ & $0,20 \mathrm{~b}$ \\
Comanche & $88,98 \mathrm{a}$ & $0,40 \mathrm{~b}$ & $2,87 \mathrm{~d}$ & $2,70 \mathrm{~d}$ & $0,17 \mathrm{c}$ \\
Ébano & $91,43 \mathrm{a}$ & $0,38 \mathrm{~b}$ & $1,85 \mathrm{f}$ & $1,76 \mathrm{f}$ & $0,09 \mathrm{f}$ \\
Guarani & $90,24 \mathrm{a}$ & $0,33 \mathrm{~b}$ & $1,96 \mathrm{f}$ & $1,84 \mathrm{f}$ & $0,12 \mathrm{e}$ \\
Tupy & $90,26 \mathrm{a}$ & $0,43 \mathrm{~b}$ & $1,60 \mathrm{~g}$ & $1,51 \mathrm{~g}$ & $0,10 \mathrm{f}$ \\
Xavante & $88,74 \mathrm{a}$ & $0,46 \mathrm{~b}$ & $3,07 \mathrm{c}$ & $2,89 \mathrm{c}$ & $0,18 \mathrm{c}$ \\
Média & 88,61 & 0,44 & 3,01 & 2,83 & 0,18 \\
CV $(\%)$ & 1,52 & 12,23 & 3,38 & 3,39 & 3,72 \\
\hline
\end{tabular}

Médias seguidas pela mesma letra nas colunas não diferem estatisticamente entre si, pelo teste de Scott-Knott, a $5 \%$ de probabilidade $(\mathrm{P} \leq 0,05)$. 
TABELA 2 -Teores médios de pectina solúvel, pectina total e porcentagem de solubilização destas pectinas, em cultivares de amoreira. UFLA, Lavras-MG, 2013.

\begin{tabular}{lccc}
\hline Espécie/Cultivares & Solubilização* (\%) & Pectina Solúvel (mg.100g $\left.{ }^{-1} \mathrm{MF}\right)$ & Pectina Total (mg.100g $\left.{ }^{-1} \mathrm{MF}\right)$ \\
\hline Amora-vermelha & $44,92 \mathrm{c}$ & $576,18 \mathrm{a}$ & $1.282,61 \mathrm{a}$ \\
Arapaho & $49,71 \mathrm{~b}$ & $476,24 \mathrm{~b}$ & $957,96 \mathrm{~b}$ \\
Brazos & $41,71 \mathrm{c}$ & $327,51 \mathrm{e}$ & $785,02 \mathrm{~d}$ \\
Caingangue & $42,79 \mathrm{c}$ & $363,50 \mathrm{~d}$ & $849,31 \mathrm{c}$ \\
Cherokee & $47,84 \mathrm{~b}$ & $378,73 \mathrm{~d}$ & $791,58 \mathrm{~d}$ \\
Choctaw & $48,42 \mathrm{~b}$ & $452,26 \mathrm{c}$ & $933,89 \mathrm{~b}$ \\
Comanche & $46,45 \mathrm{~b}$ & $447,27 \mathrm{c}$ & $962,77 \mathrm{~b}$ \\
Ébano & $60,69 \mathrm{a}$ & $366,85 \mathrm{~d}$ & $605,36 \mathrm{e}$ \\
Guarani & $41,97 \mathrm{c}$ & $351,81 \mathrm{~d}$ & $838,16 \mathrm{c}$ \\
Tupy & $49,48 \mathrm{~b}$ & $469,83 \mathrm{~b}$ & $949,50 \mathrm{~b}$ \\
Xavante & $62,21 \mathrm{a}$ & $488,70 \mathrm{~b}$ & $785,55 \mathrm{~d}$ \\
\hline Média & 48,77 & 427,17 & 885,60 \\
CV (\%) & 5,92 & 4,61 & 3,18 \\
\hline
\end{tabular}

Médias seguidas pela mesma letra nas colunas não diferem estatisticamente entre si, pelo teste de Scott-Knott, a 5\% de probabilidade $(\mathrm{P} \leq 0,05)$.

*A solubilização da pectina foi calculada pela porcentagem de pectina solúvel em relação à pectina total.

TABELA 3- Teores médios de fenóis totais, flavonoides, antocianinas, licopeno, $\beta$ - caroteno, vitamina A e atividade antioxidante (AA) em frutos de cultivares de amoreira. UFLA, Lavras-MG, 2013.

\begin{tabular}{|c|c|c|c|c|c|c|c|}
\hline \multirow[t]{2}{*}{$\begin{array}{l}\text { Espécie/ } \\
\text { Cultivares } \\
\text { Amora- vermelha }\end{array}$} & $\begin{array}{l}\text { Fenóis } \\
\text { Totais } \\
-\end{array}$ & \multicolumn{2}{|c|}{$\begin{array}{l}\text { Flavonoides Antocianina } \\
\text { mg.100 } \mathrm{g}^{-1} \mathrm{MF} \text {-------- }\end{array}$} & \multicolumn{2}{|c|}{$\begin{array}{c}\text { Licopeno } \beta \text {-caroteno } \\
\text { mcg. } 100 \mathrm{~g}^{-1} \mathrm{MF}\end{array}$} & \multirow{2}{*}{$\begin{array}{c}\text { Vit. A } \\
\text { mcg. } 100^{-1} \mathrm{gMF} \\
28,28 \mathrm{a}\end{array}$} & \multirow{2}{*}{$\begin{array}{c}\mathrm{AA} \\
\mathrm{EC}_{50} \\
2.52 \mathrm{~d}\end{array}$} \\
\hline & $1.093,22 \mathrm{a}$ & $136,07 \mathrm{a}$ & $92,96 \mathrm{~h}$ & - & $336,70 \mathrm{a}$ & & \\
\hline Arapaho & $433,53 \mathrm{~d}$ & $89,55 \mathrm{e}$ & $503,64 \mathrm{c}$ & $63,30 \mathrm{c}$ & $229,89 \mathrm{~b}$ & $19,31 \mathrm{~b}$ & $2,27 \mathrm{e}$ \\
\hline Brazos & $324,51 \mathrm{e}$ & $95,34 \mathrm{~d}$ & $310,55 \mathrm{~g}$ & $40,09 \mathrm{e}$ & $10,45 \mathrm{~h}$ & $0,87 \mathrm{~h}$ & $3,67 \mathrm{~b}$ \\
\hline gue & $441,70 \mathrm{~d}$ & 8 & e & $48,93 \mathrm{~d}$ & - & - & $2,52 \mathrm{~d}$ \\
\hline Cherokee & $433,53 \mathrm{~d}$ & $79,21 \mathrm{~g}$ & $364,87 \mathrm{e}$ & $49,81 \mathrm{~d}$ & 48,8 & 4,10 & $3,00 \mathrm{c}$ \\
\hline Choctaw & $252,65 \mathrm{~g}$ & $102,70 \mathrm{c}$ & $292,90 \mathrm{~g}$ & $37,25 \mathrm{f}$ & $151,43 \mathrm{~d}$ & $12,72 \mathrm{~d}$ & $3,17 \mathrm{c}$ \\
\hline Comanche & $285,86 \mathrm{~g}$ & $77,35 \mathrm{~h}$ & $373,52 \mathrm{~d}$ & $70,43 \mathrm{~b}$ & $79,87 \mathrm{e}$ & $6,71 \mathrm{e}$ & $4,27 \mathrm{a}$ \\
\hline Ébon & $483,30 \mathrm{c}$ & $5 d$ & & 26 & $147,73 \mathrm{~d}$ & $12,41 \mathrm{~d}$ & $1,33 \mathrm{f}$ \\
\hline rani & & & & & & 1 , & $2,98 \mathrm{c}$ \\
\hline Tupy & $247,33 \mathrm{~g}$ & 60, & 37 & 35 & $32,28 \mathrm{~g}$ & $2,71 \mathrm{~g}$ & $3,54 \mathrm{~b}$ \\
\hline Xavante & $671,45 \mathrm{~b}$ & $128,53 \mathrm{~b}$ & $531,23 \mathrm{~b}$ & $91,62 \mathrm{a}$ & $183,24 \mathrm{c}$ & $15,39 \mathrm{c}$ & $2,30 \mathrm{e}$ \\
\hline Média & 437,72 & 92,94 & 380,30 & 44,96 & 123,81 & 10,40 & 2,86 \\
\hline CV (\%) & 1,29 & 1,05 & 4,53 & 4,54 & 5,16 & 5,16 & 4,65 \\
\hline
\end{tabular}

Médias seguidas pela mesma letra nas colunas não diferem estatisticamente entre si, pelo teste de Scott-Knott, a 5\% de probabilidade $(\mathrm{P} \leq 0,05) . \mathrm{EC}_{50}=$ Concentração do extrato necessária para inibir a oxidação do radical DPPH em $50 \%$.

TABELA 4- Estimativa das distâncias Eucledianas médias de dissimilaridade entre os genótipos de amora estudados, quantificadas pela distância generalizada de Mahalanobis $\left(\mathrm{D}^{2}\right)$. UFLA, LavrasMG, 2013.

\begin{tabular}{lccccccccccc}
\hline Espécie/Cultivares & 1 & 2 & 3 & 4 & 5 & 6 & 7 & 8 & 9 & 10 & 11 \\
\hline Amora-vermelha & 0 & 2,34 & 2,50 & 2,43 & 2,34 & 2,08 & 2,29 & 2,75 & 2,52 & 2,50 & 2,32 \\
Arapaho & & 0 & 1,00 & 1,03 & 1,02 & 1,03 & 0,72 & 1,22 & 1,09 & 1,11 & 0,83 \\
Brazos & & & 0 & 0,87 & 0,85 & 0,97 & 0,71 & 1,37 & 0,50 & 0,83 & 1,23 \\
Caingangue & & & & 0 & 0,91 & 1,19 & 0,78 & 1,07 & 0,87 & 1,06 & 1,16 \\
Cherokee & & & & & 0 & 1,10 & 0,74 & 1,36 & 0,96 & 1,10 & 0,97 \\
Choctaw & & & & & & 0 & 0,79 & 1,57 & 1,04 & 1,01 & 1,23 \\
Comanche & & & & & & 0 & 1,21 & 0,78 & 0,83 & 1,00 \\
Ébano & & & & & & & 0 & 1,36 & 1,53 & 1,35 \\
Guarani & & & & & & & & 0 & 0,75 & 1,31 \\
Tupy & & & & & & & & & & 0 & 1,37 \\
Xavante & & & & & & & & & & &
\end{tabular}


TABELA 5- Grupos com padrões similares estabelecidos pelo método de otimização de Tocher, aplicado a distância Euclideana Média, em 23 características de 10 cultivares de amoreira preta e 1 espécie de amoreira-vermelha. UFLA, Lavras-MG, 2013.

\begin{tabular}{ccc}
\hline Grupos & Número de Indivíduos & Cultivar e /ou espécie \\
\hline I & 10 & Arapaho, Brazos, Caingangue, Cherokee, Choctaw, Comanche, \\
II & 1 & Ébano, Guarani, Tupy e Xavante \\
\hline
\end{tabular}

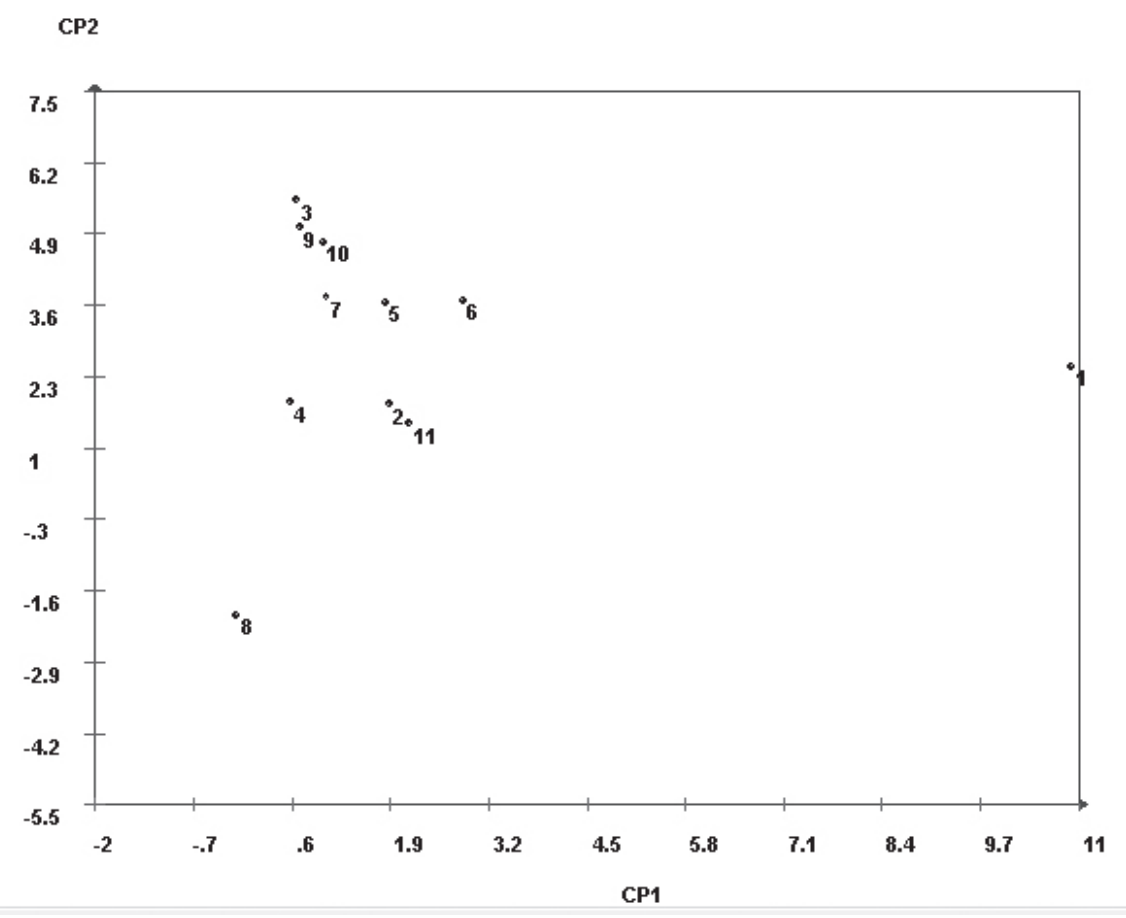

FIGURA1- Dispersão gráfica dos escores em relação aos dois eixos representativos das duas primeiras variáveis canônicas $\left(\mathrm{CP}_{1}\right.$ e $\left.\mathrm{CP}_{2}\right)$ para as cultivares de amora estudadas, em que: 1 (AmoraVermelha), 2. (Arapaho), 3 (Brazos), 4 (Caingangue), 5(Cherokee), 6 (Choctaw), 7 (Comanche), 8 (Ébano), 9 (Guarani), 10 (Tupy), 11 (Xavante). UFLA, Lavras-MG, 2013. 

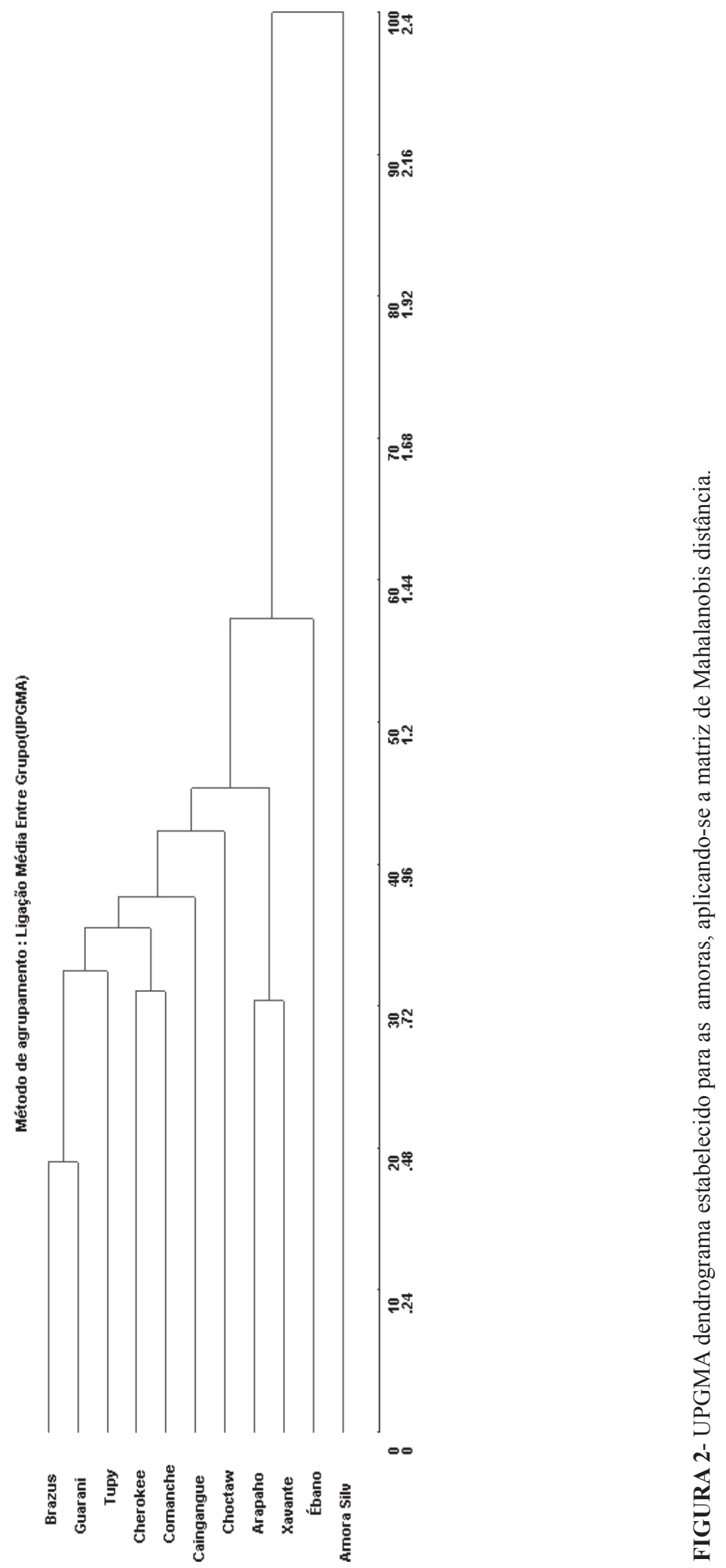


\section{CONCLUSÕES}

1-Frutos da amoreira-vermelha apresentam maiores quantidades das propriedades químicas avaliadas. A atividade sequestradora do radical DPPH variou de acordo com a cultivar.

2-Recomenda-se aos programas de melhoramento genético da amoreira a incorporação da cultivar Ébano e espécie de amoreira-vermelha, por apresenar características distintas, que visem à obtenção de frutos de características similares aos progenitores, principalmente aos compostos bioativos.

\section{REFERÊNCIAS}

ACOSTA-MONTOYA, O; VAILLANT, F.; COZZANO, S.; MERTZ, C.; PÉREZ, A.M.; CASTRO, M.V. Phenolic content and antioxidant capacity of tropical highland blackberry (Rubus adenotrichus Schltdl.) during three edible maturity stages. Food Chemistry, Reading, v.119, n.4, p.1.497-1.501, 2010.

ALI, L.; SVENSSON, B.; ALSANIUS, B.W.; OLSSON, M.E. Late season harvest and storage of Rubus berries - Major antioxidant and sugar Levels. Scientia Horticulturae, Amsterdam, v.129, n.3, p.376-381, 2011.

ANTUNES, L.E.C.; GONÇALVES, E.D.; TREVISAN, R. Alterações de compostos fenólicos e pectina em pós-colheita de frutos de amora-preta. Revista Brasileira de Agrociência, Pelotas, v.12, n.1, p.57-61, 2006.

CAMPAGNOLO, M.A.; PIO, R. Phenological and yield performance of black and redberry cultivars in western Paraná State. Acta Scientiarum. Agronomy, Maringá, v.34, n.4, p.439-444, 2012 b.

CAMPAGNOLO, M.A.; PIO, R. Produção da amoreira-preta 'Tupy' sob diferentes épocas de poda. Ciência Rural, Santa Maria, v.42, n.2, p.225231, 2012a.

CHIANG, F.; JU, H.; WROLSTAD, R.E. Anthocyanin Pigment composition of blackberries. Journal of Food Science, Chicago, v.70, n.3, p.198-202, 2005.
FERREIRA, D.F. Sisvar: a computer statistical analysis system. Ciência e Agrotecnologia, Lavras, v.35, n.6, p.1.039-1.042, 2011.

FIGUEIREDO, M.A.; PIO, R.; SILVA, T.C.; SILVA, K.N. Características florais e carpométricas e germinação in vitro de grãos de pólen de cultivares de amoreira-preta. Pesquisa Agropecuária Brasileira, Brasília, v.48, n.7, p.731-740, 2013.

GUEDES, M.N.S.; ABREU, C.M.P.; MARO, L.A.C.; PIO, R.; ABREU, J.R.; OLIVEIRA, J.O. Chemical characterization and mineral levels in the fruits of blackberry cultivars grown in a tropical climate at an elevation. Acta Scientiarum. Agronomy, Maringá, v.35, n.2, p.191-196, 2013.

KAFKAS, E.; KOSAR, M.; TUREMIS, N.; BASER, K.H.C. Analysis of sugars, organic acids and vitamin $\mathrm{C}$ contents of blackberry genotypes from Turkey. Food Chemistry, Reading, v.97, n.4, p.732-736, 2006.

MARO, L.A.C.; PIO, R.; GUEDES, M.N.S.; ABREU, C.M.P.; CURI, P.N. Bioactive compounds, antioxidant activity and mineral composition of fruits of raspberry cultivars grown in subtropical areas in Brazil. Fruits, Paris, v.68, n.3, p. 209-217, 2013.

MORITZ, B.; TRAMONTE, V.L.C. Biodisponibilidade do licopeno. Revista de Nutrição, Campinas, v.19, n.2, p.265-273, 2006.

TOSUN, I.; U.N.; SULE, U.N.; BELKIS, T. Physical and chemical changes during ripening of blackberry fruits. Scientia Agricola, Piracicaba, v.65, n.1, p.8790, 2008. 